\title{
RESEARCH
}

Open Access

\section{Bell's palsy: clinical and neurophysiologic predictors of recovery}

Mohamed E. Flifel ${ }^{1 *}$, Tamer Belal ${ }^{1}$ and Ali A. Abou Elmaaty ${ }^{2}$

\begin{abstract}
Background: The annual incidence of Bell's palsy (BP) is 15 to 20 per 100,000 with 40,000 new cases each year, and the lifetime risk is 1 in 60. For decades, clinicians have searched the prognostic tests of sufficient accuracy for acute facial paralysis.

Objective: The present study was designed to verify in BP which clinical or electrophysiological parameters could be considered as predictive of the degree of recovery of normal facial muscle function.

Methods: Sixty-three patients with BP were initially assessed according to the House and Brackmann facial function scoring system "HB system". All patients were followed for 3 months, the functional recovery then reassessed according to HB system. Nerve conduction studies were measured on the affected side via a bipolar surface stimulator placed over the stylomastoid foramen.

Results: We could not find statistically significant differences between BP with good and poor prognosis as regard age, sex, onset, diabetes, hypertension, dyslipidemia, or the initial HB Score. Compound motor action potential amplitude (CMAP) detected during the initial electroneurography (ENoG) was statistically significant between BP with good and poor prognosis.

Conclusions: The initial ENoG is more predictive of recovery of Bell's palsy than the initial clinical grading using the HB system. Age, sex, hypertension, diabetes, and dyslipidemia do not seem to correlate with the degree of recovery in Bell's palsy.
\end{abstract}

Keywords: Bell's palsy, HB system, CMAP, ENoG

\section{Introduction}

Bell's palsy (BP) is mostly idiopathic, but viral infections as herpes simplex virus, varicella-zoster virus, and Epstein-Barr virus are suggested [1].The incidence is 15 to 20 per 100,000 . The recurrence rate is about $10 \%$ [2].The pathophysiology of Bell's palsy includes compression of facial nerve at the internal auditory meatus, due to the inflammatory edema leading to temporary loss of sensory or motor function, but it could lead to permanent nerve degeneration later [3].

There are several studies suggesting the association between diabetes, hypertension, and hypercholesterolemia

\footnotetext{
*Correspondence: me_neuro2020@yahoo.com

${ }^{1}$ Mansoura University Hospital, Mansoura University, Mansoura, Egypt

Full list of author information is available at the end of the article
}

with poor prognosis of Bell's palsy; however, other studies did not find this association [4-6]. The advanced grade of BP at the time of presentation is associated with poor prognosis [7].

The House and Brackmann (HB) grading system is the most widely accepted system for measurement of the facial nerve functions [8]. The American Academy of Otolaryngology-Head and Neck Surgery adopted this scale as a universal standard for grading facial nerve recovery [9].

The prognosis of Bell's palsy has been predicted based mainly on various electrophysiologic tests especially electroneurography "ENoG" [10]. ENoG can determine the percentage of degenerating nerve fibers in early phase of acute facial paralysis. Various studies [11-13] 
have shown that ENoG can be used to predict the prognosis of acute facial paralysis.

The present study was designed to verify which clinical or electrophysiological parameters could be considered as predictive of the degree of recovery of patients with Bell's palsy.

\section{Subjects and methods Subjects}

This observational study was carried out during the period from November 2017 to September 2018 in Neurology Department, Mansoura University Hospital. The study included 63 patients with Bell's palsy.

\section{Inclusion criteria}

Inclusion criteria were adults aged between 18 and 70 years with unilateral BP and standardized oral pharmacological treatment within $48 \mathrm{~h}$.

\section{Exclusion criteria}

Exclusion criteria were any sign of infective, central, and peripheral nervous system disease or temporal bone pathologies.

\section{Methods}

\section{Clinical evaluation}

\section{Informed consent}

All patients signed a written consent before included in the study. History taking and complete neurological examination were done at the outpatient clinic of the department of neurology at Mansoura University Hospital.

\section{Diagnosis of diabetes, hypertension, and dyslipidemia}

Diabetes, hypertension, and dyslipidemia were defined according to the guidelines from the National Heart, Lung, and Blood Institute and the American Heart Association [14]:

1- Diabetes: Fasting blood glucose level was $\geq 100 \mathrm{mg} /$ $\mathrm{dl}$ or using insulin or oral hypoglycemic agents.

2- Hypertension: Elevated blood pressure (systolic blood pressure $\geq 130 \mathrm{mmHg}$ and/or diastolic blood pressure $\geq 85 \mathrm{mmHg}$ or current use of antihypertensive drugs).

3- Dyslipidemia: Hypertriglyceridemia (triglycerides $\geq$ $150 \mathrm{mg} / \mathrm{dl}$ ) and/or use of cholesterol lowering medications; low HDL cholesterol (HDL cholesterol $<40 \mathrm{mg} / \mathrm{dl}$ for men and $<50 \mathrm{mg} / \mathrm{dl}$ for women).

\section{House and Brackmann (HB) facial scoring system}

Bell's palsy in all patients was initially assessed according to the House and Brackmann facial scoring system "HB system". It is a 6-point scale intended for categorizing overall facial nerve function from normal to complete paralysis (grades 1-6) [8]. All patients were followed for 3 months; the functional recovery then reassessed according to HB system and divided into: grades 1 and 2: complete recovery, grade 3 : incomplete recovery, grades 4 and 5: poor recovery [15].

\section{Electrophysiology}

Nerve conduction studies were measured on the affected side using neuropack 2 Nihon Kohden Japan, model MEB/MEM. 7102A/K02 surface electrode recording was done using surface electrodes placed over the frontalis, nasalis, and orbicularis oculi muscles, increasing current intensity to evoke compound muscle action potential. Distal latency and amplitude of the response were determined [16].

\section{Statistical analysis}

The collected data were coded, processed, and analyzed using the SPSS (Statistical Package for Social Sciences) version 15 Windows (SPSS Inc, Chicago, IL, USA). Qualitative data were presented as number and percent. Comparison between groups was done by Chi-Square test. Quantitative data was presented as mean \pm SD. Student $t$ test was used to compare between two groups. Non parametric data was presented as min-max and median. Mann-Whitney test was used for comparison between groups. $p<0.05$ was considered to be statistically significant.

\section{Results}

The House-Brackmann (HB) grading system at the onset and after 3 months was used for the clinical evaluation of Bell's palsy. We classified our patients into 2 groups; group 1 (good prognosis) with $\mathrm{HB}$ grade 1 or 2 in the third month of clinical follow-up and group 2 (poor prognosis) with grade 3 or higher.

The demographic and clinical characteristics of the 63 studied patients are summarized in Table 1 . There were no statistically significant differences between the 2 groups as regards age at onset and sex $(p=0.946$ and $p$ $=0.441$ respectively). There were 52 patients with good prognosis (group 1) and 11 patients with poor prognosis (group 2)

Thirty-five patients $(67.3 \%)$ in group 1 and 8 patients (72.7\%) presented within 3 days of onset with no statistically significant differences between the 2 groups $(p=$ 0.726). Seventeen patients in group 1 and 3 patients in group 2 presented within the first 10 days of onset. There were no statistically significant differences between group 1 and 2 as regards diabetes, hypertension, and dyslipidemia $(p=0.207, p=0.622$, and $p=0.941$ (respectively)) (Table 1).

Initial $\mathrm{HB}$ was $5.17 \pm 0.90$ in group 1 and $5.55 \pm 0.52$ in group 2 with no statistically significant differences 
Table 1 Demography and clinical characteristics

\begin{tabular}{|c|c|c|c|}
\hline $\begin{array}{l}\text { Demography and clinical } \\
\text { characteristics }\end{array}$ & $\begin{array}{l}\text { Group } 1 \\
(N=52)\end{array}$ & $\begin{array}{l}\text { Group } 2 \\
(N=11)\end{array}$ & $p$ \\
\hline Age: mean $\pm S D$ & $\begin{array}{l}45.79 \pm \\
18.01\end{array}$ & $\begin{array}{l}46.18 \pm \\
14.80\end{array}$ & 0.946 \\
\hline \multicolumn{4}{|l|}{ Sex } \\
\hline Male: $N(\%)$ & $26(50 \%)$ & $7(63.6 \%)$ & \multirow[t]{2}{*}{0.411} \\
\hline Female: N (\%) & $26(50 \%)$ & $4(36.4 \%)$ & \\
\hline \multicolumn{4}{|l|}{ Treatment after onset: } \\
\hline$\leq 3$ days: $N(\%)$ & $35(67.3 \%)$ & $8(72.7 \%)$ & \multirow[t]{2}{*}{0.726} \\
\hline > 3 days: $N(\%)$ & $17(32.7 \%)$ & $3(27.3)$ & \\
\hline \multicolumn{4}{|l|}{ Diabetes } \\
\hline No: $N(\%)$ & $25(48.1 \%)$ & $3(27.3 \%)$ & \multirow[t]{2}{*}{0.207} \\
\hline Yes: $N(\%)$ & $27(51.9 \%)$ & $8(72.7)$ & \\
\hline \multicolumn{4}{|l|}{ Hypertension } \\
\hline No: N (\%) & $37(71.2 \%)$ & $7(63.6 \%)$ & \multirow[t]{2}{*}{0.622} \\
\hline Yes: N (\%) & $15(28.8 \%)$ & $4(36.4)$ & \\
\hline \multicolumn{4}{|l|}{ Dyslipidemia } \\
\hline No: N (\%) & $29(55.8 \%)$ & $6(54.5 \%)$ & \multirow[t]{2}{*}{0.941} \\
\hline Yes: $N(\%)$ & $23(44.2 \%)$ & $5(45.5 \%)$ & \\
\hline Initial HB: mean \pm SD & $5.17 \pm 0.90$ & $5.55 \pm 0.52$ & 0.192 \\
\hline HB after 3 months: mean \pm SD & $1.44 \pm 0.50$ & $3.18 \pm 0.40$ & $\begin{array}{l}< \\
0.001^{*}\end{array}$ \\
\hline
\end{tabular}

SD standard deviation, HB House-Brackmann

*Highly significant

between the 2 groups $(p=0.192)$ while $\mathrm{HB}$ after 3 months was $1.44 \pm 0.50$ in group 1 and $3.18 \pm 0.40$ in group 2 with statistically significant differences between both groups $(p<0.001)$ (Table 1$)$.

Neurophysiological characteristics are shown in Table 2. The mean CMAP latency of frontalis muscle was $3.79 \pm 0.79 \mathrm{~ms}$ in group 1 and $4.04 \pm 0.92 \mathrm{~ms}$ in group 2 with no statistically significant differences between both groups $(p=0.308)$. The mean CMAP amplitude of frontalis muscle was $1.06 \pm 0.69$ in

Table 2 Neurophysiological characteristics

\begin{tabular}{llll}
\hline Neurophysiological characteristics & $\begin{array}{l}\text { Group 1 } \\
(N=52)\end{array}$ & $\begin{array}{l}\text { Group 2 } \\
(\mathrm{N}=11)\end{array}$ & $p$ \\
\hline Frontalis muscle & & & \\
$\quad$ Latency: mean \pm SD (ms) & $3.79 \pm 0.79$ & $4.04 \pm 0.92$ & 0.308 \\
$\quad$ Amplitude: mean \pm SD (mv) & $1.06 \pm 0.69$ & $0.31 \pm 0.17$ & $<\mathbf{0 . 0 0 1 *}$ \\
Nasalis muscle & & & \\
$\quad$ Latency: mean \pm SD (ms) & $3.68 \pm 0.62$ & $3.95 \pm 0.8$ & 0.178 \\
$\quad$ Amplitude: mean \pm SD (mv) & $1.40 \pm 0.7$ & $0.85 \pm 0.21$ & $\mathbf{0 . 0 0 1 *}$ \\
Orbicularis oris muscle & & & \\
$\quad$ Latency: mean \pm SD (ms) & $3.91 \pm 0.50$ & $4.23 \pm 0.83$ & 0.101 \\
Amplitude: mean \pm SD (mv) & $1.27 \pm 0.59$ & $0.80 \pm 0.25$ & $\mathbf{0 . 0 0 1 *}$ \\
\hline
\end{tabular}

ms millisecond, $m v$ millivolt

*Highly significant group 1 and $0.31 \pm 0.17$ in group 2 with statistically significant differences between both groups $(p<$ 0.001) (Table 2).

The mean CMAP latency of nasalis muscle was $3.68 \pm$ $0.62 \mathrm{~ms}$ in group 1 and $3.95 \pm 0.8 \mathrm{~ms}$ in group 2 with no statistically significant differences between both groups $(p=0.178)$. The mean CMAP amplitude of nasalis muscle was $1.40 \pm 0.7$ in group 1 and $0.85 \pm 0.21$ in group 2 with statistically significant differences between both groups $(p=0.001)$ (Table 2).

The mean CMAP latency of orbicularis oris muscle was $3.91 \pm 0.50 \mathrm{~ms}$ in group 1 and $4.23 \pm 0.83 \mathrm{~ms}$ in group 2 with no statistically significant differences between both groups $(p=0.101)$. The mean CMAP amplitude of orbicularis muscle was $1.27 \pm 0.59$ in group 1 and $0.80 \pm 0.25$ in group 2 with statistically significant differences between both groups $(p=0.001)$ (Table 2).

\section{Discussion}

There is a great difference in the response of patients with Bell's palsy to treatment and it would be beneficial if we have a tool to predict its outcome since facial nerve is very important for facial expression $[17,18]$. There are many studies for early prediction of outcome of Bell's palsy but these studies are difficult to compare due to variation in design and selection criteria $[19,20]$.

In our study, we could not find statistically significant differences between patients with Bell's palsy with good prognosis and poor prognosis as regards age $(p=0.946)$ and sex $(p=0.411)$. These findings are in agreement with previous studies which found no significant relationship between Bell's palsy prognosis, age, and sex [21-23], although Ikeda et al. found that age and gender may affect the progression of Bell's palsy [24].

In our work, there were no statistically significant differences between the 2 groups as regards the start of treatment after the onset of BP $(p=0.726)$. There are few studies for the relationship between the time of treatment of Bell's palsy and its prognosis. In contrast to our findings, Yeo et al. found that treatment within 3 days has been associated with better outcome than later treatment [25]. Treatment within first day of onset has been found to have good outcome in a study of patients with severe Bell's palsy [26].

In our study, there were no statistically significant differences between group1 (good prognosis) and group 2 (poor prognosis) as regards diabetes, hypertension, or dyslipidemia $(p>0.05)$. In accordance to our findings, some authors found that diabetes in patients with Bell' palsy is not higher than in the general population [27-29]. For example, Kudoh et al. reported that Bell's palsy scores are not affected by diabetes or hypertension, although patients with both diabetes and hypertension had poorer recovery [30]. In 
contrast to our findings, recovery from Bell's palsy in diabetic patients was found to be poor compared to non-diabetic patients and the maximum treatments might be beneficial in these patients [4].

In another study, the recovery rate of Bell's palsy was correlated with diabetes and high triglycerides [31]. Fujiwara et al. reported no correlation between diabetes mellitus and non-recovery from Bell's palsy [32]. Abraham et al. have found the presence of hypertension as a poor prognostic indicator for patients with Bell's palsy [7].

In our study, there were no statistically significant differences between the 2 groups as regards the initial total HB score $(p=0.192)$ while total HB score after 3 months was statistically significant between both groups $(p<$ 0.001). In contrast to our findings, Coulson et al. found that the initial HB grading on a single clinical examination could be used to determine the prognosis of Bell's palsy [33].

Our work showed less decrease in the amplitude of frontalis, nasalis, and orbicularis oris muscles in group 1 (good prognosis) than group 2 (poor prognosis) with statistically significant difference $(p=<0.001$ for frontalis, $p=0.001$ for nasalis, $p=0.001$ for orbicularis oris). The terminal latency showed no significant differences between the two groups ( $p=0.308$ for frontalis, $p=0.178$ for nasalis, $p=0.101$ for orbicularis oris). Several studies have found a special prognostic value of the amplitude of the compound muscle action potential (CMAP) in Bell's palsy. For example, May et al. showed that amplitude reductions less than $10 \%$ were highly associated with poor recovery [34]. Gantz et al. showed that patients who reached $90 \%$ degeneration on ENoG within 2 weeks of onset returned to $\mathrm{HB}$ grade 1 or 2 within 7 months [35]. Fisch reported good recovery in half of patients with $90 \%$ or more ENoG degeneration and $80 \%$ recovery in patients with less than 90\% degeneration [11]. The diagnostic and prognostic value of the CMAP latency was discussed in other studies, since the CMAP latency determines the viability of the fast axons, so it can remain within a normal range for a long time [21].

\section{Conclusions}

The initial electroneurography (ENoG) is more predictive of recovery of Bell's palsy than the initial clinical grading using the House-Brackmann (HB) grading system. Age, sex, hypertension, diabetes, and dyslipidemia do not seem to correlate with the degree of recovery in Bell's palsy.

\section{Acknowledgements}

Not applicable.

\section{Authors' contributions}

MEF, TB, and AAM carried out the work. All designed the study and collected the patients and gathered the clinical data. AAM did the statistical analysis. MEF was responsible for collecting the scientific data and writing the initial draft of the manuscript. All authors read and approved the final version to be published.

Funding

There is no source of funding for the research.

Availability of data and materials

The data supporting the results of this article are included within the article.

\section{Ethics approval and consent to participate}

The authors obtained permission to conduct this study from the Institutional Review Board, Mansoura Faculty of Medicine, Mansoura University (codeNumber:R/18.12.370) on January 2019. An informed consent was obtained from all the patients studied.

\section{Consent for publication}

Not applicable.

\section{Competing interests}

The authors declare that they have no competing interests.

\section{Author details}

${ }^{1}$ Mansoura University Hospital, Mansoura University, Mansoura, Egypt. ${ }^{2}$ Badr University Hospital, Helwan University, Helwan, Egypt.

Received: 26 February 2019 Accepted: 30 March 2020

Published online: 10 April 2020

\section{References}

1. Spencer CR, Irving RM. Causes and management of facial nerve palsy. Br J Hosp Med (Lond). 2016;77(12):686-91.

2. Zhao H, Zhang X, Tang YD, Zhu J, Wang XH, Li ST. Bell's palsy: clinical analysis of 372 cases and review of related literature. Eur Neurol. 2017;77(34):168-72.

3. Zandian A, Osiro S, Hudson R, et al. The neurologist's dilemma: a comprehensive clinical review of Bell's palsy, with emphasis on current management trends. Med Sci Monit. 2014;20:83-90.

4. Kanazawa A, Haginomori S, Takamaki A, Nonaka R, Araki M, Takenaka H. Prognosis for Bell's palsy: a comparison of diabetic and nondiabetic patients. Acta Otolaryngol. 2007;127:888-91.

5. Hsieh RL, Wu CW, Wang LY, Lee WC. Correlates of degree of nerve involvement in early Bell's palsy. BMC Neurol. 2009;9:22.

6. Riga M, Kefalas's $G$, Danielides $V$. The role of diabetes mellitus in the clinical presentation and prognosis of Bell palsy. J Am Board Fam Med. 2012;25: 819-26.

7. Abraham-Inpijn L, Oosting J, Hart AA. Bell's palsy: factors affecting the prognosis in 200 patients with reference to hypertension and diabetes mellitus. Clin Otolaryngol Allied Sci. 1987;12:349-55.

8. House JW, Brakmann DE. Facial nerve grading system. Otolaryngol Head Neck Surg. 1985;93:146-7.

9. LeeD H. Clinical efficacy of electroneurography in acute facial paralysis. J Audiol Otol. 2016;20(1):8-12.

10. Thomander $L$, Stälberg E. Electroneurography in the prognostication of Bell's palsy. Acta Otolaryngol. 1981;92:221-37.

11. Fisch U. Prognostic value of electrical tests in acute facial paralysis. Am J Otolaryngol. 1984;5:494-8.

12. Sillman JS, Niparko JK, Lee SS, Kileny PR. Prognostic value of evoked and standard electromyography in acute facial paralysis. Otolaryngol Head Neck Surg. 1992;107:377-81.

13. Smith IM, Maynard C, Mountain RE, Barr-Hamilton R, Armstrong M, Murray JA. The prognostic value of facial electroneurography in Bell's palsy. Clin Otolaryngol Allied Sci. 1994;19:201-3.

14. Alberti KG, Eckel RH, Grundy SM, et al. Harmonizing the metabolic syndrome: a joint interim statement of the International Diabetes Federation Task Force on Epidemiology and Prevention; National Heart, Lung, and Blood Institute; American Heart Association; World Heart Federation; International Atherosclerosis Society; and International Association for the Study of Obesity. Circulation. 2009;120(16):1640-5.

15. Vrabec JT, Backous DD, Djalilian HR, et al. Facial nerve grading system. Otolaryngol Head Neck Surg. 2009;140:445-50. 
16. Valls-Sole J. Electrodiagnostic studies of the facial nerve in peripheral facial palsy and hemifacial spasm. Muscle Nerve. 2007;36:14-20.

17. Dong Y, Zhu Y, Ma C, Zhao H. Steroid-antivirals treatment versus steroids alone for the treatment of Bell's palsy: a meta-analysis. Int J ClinExp Med. 2015;8:413-21

18. Giri P, Garg RK, Singh MK, Verma R, Malhotra HS, Sharma PK. Single dose intravenous methyl prednisolone versus oral prednisolone in Bell's palsy: a randomized controlled trial. Indian J Pharm. 2015;47:143-7.

19. Mantsopoulos K, Psillas G, Psychogios G, Brase C, Iro H, Constantinidis J. Predicting the long-term outcomes after idiopathic facial nerve paralysis. Otol Neurotol. 2011:32:848-51.

20. Morishima N, Yagi R, Shimizu K, Ota S. Prognostic factors of synkinesis after Bell's palsy and Ramsay Hunt syndrome. Auris Nasus Larynx. 2013;40:431-4.

21. Takashi F, Naohito H, Kiyofumi G, Naoaki Y. Prognostic factors of Bell's palsy: prospective patient collected observational study. Eur Arch Otorhinolaryngol. 2014;271:1891-5.

22. Happe S, Bunten S. Electrical and transcranial magnetic stimulation of the facial nerve: diagnostic relevance in acute isolated facial nerve palsy. EurNeurol. 2012;68:304-9.

23. Prakash KM, Raymond AA. The use of nerve conduction studies in determining the short-term outcome of Bell's palsy. Med J Malaysia. 2003; 58:69-78.

24. Ikeda M, Abiko Y, Kukimoto N, Omori H, Nakazato H, Ikeda K. Clinical factors that influence the prognosis of facial nerve paralysis and the magnitudes of influence. Laryngoscope. 2005;115:855-60.

25. Yeo SG, Lee YC, Park DC, et al. Acyclovir plus steroid vs steroid alone in the treatment of Bell's palsy. Am J Otolaryngol. 2008;29(3):163-6.25.

26. Shafshak TS, Essa AY, Bakey FA. The possible contributing factors for the success of steroid therapy in Bell's palsy: a clinical and electrophysiological study. J Laryngol Otol. 1994;108(11):940-3.

27. Martinez A. Diabetic neuropathy. Topography, general electrophysiologic features, effect of ischemia on nerve evoked potential and frequency of the entrapment neuropathy. Electromyogr Clin Neurophysiol. 1986;26:283-95.

28. Stamboulis E, Vassilopoulos D, Kalfakis N. Symptomatic focal mononeuropathies in diabetic patients: increased or not? J Neurol. 2005; 252:448-52.

29. Kiziltan ME, Uluduz D, Yaman M, Uzun N. Electrophysiological findings of acute peripheral facial palsy in diabetic and non-diabetic patients. Neurosci Lett. 2007:418:222-6.

30. Kudoh A, Ebina E, Kudo H, Matsuki A. Delayed recovery of patients with Bell's palsy complicated by non-insulin-dependent diabetes mellitus and hypertension. Eur Arch Otorhinolaryngol. 1998;255:166-7.

31. Jung SY, Jung J, Byun JY, Park MS, Kim SH, Yeo SG. The effect of metabolic syndrome on Bell's palsy recovery rate. Acta Otolaryngol. 2018;138(7):670-4. https://doi.org/10.1080/00016489.2018.1425902.

32. Fujiwara T, Hato N, Gyo K, Yanagihara N. Prognostic factors of Bell's palsy: prospective patient collected observational study. Eur Arch Otorhinolaryngol. 2013;271(7):1891-5. https://doi.org/10.1007/s00405-0132676-9.

33. Coulson S, Croxson GR, Adams R, Oey V. Prognostic factors in herpes zoster oticus (Ramsay Hunt Syndrome). Otology \& Neurotology. 2011;32(6):102530. https://doi.org/10.1097/mao.0b013e3182255727.

34. May M, Blumenthal F, Klein SR, et al. Acute Bell's palsy: prognostic value of evoked electromyography, maximal stimulation, and other electrical tests. Am J Otolaryngol. 1983;5:1-7.

35. Gantz BJ, Gmuer AA, Holliday M, Fisch U. Electroneurographic evaluation of the facial nerve. Method and technical problems. Ann Otol Rhinol Laryngol. 1984;93:394-8

\section{Publisher's Note}

Springer Nature remains neutral with regard to jurisdictional claims in published maps and institutional affiliations.

\section{Submit your manuscript to a SpringerOpen ${ }^{\circ}$ journal and benefit from:}

- Convenient online submission

- Rigorous peer review

- Open access: articles freely available online

- High visibility within the field

- Retaining the copyright to your article

Submit your next manuscript at $\boldsymbol{\nabla}$ springeropen.com 